Acta Crystallographica Section D

\section{Biological Crystallography}

ISSN 1399-0047

\section{Petri Kursula}

Department of Biochemistry and Biocenter Oulu, University of Oulu, Oulu, Finland, and Department of Chemistry, University of Hamburg, Hamburg, Germany

Correspondence e-mail: petri.kursula@oulu.fi

\title{
Crystallographic snapshots of initial steps in the collapse of the calmodulin central helix
}

Calmodulin is one of the most well characterized proteins and a widely used model system for calcium binding and largescale protein conformational changes. Its long central helix is usually cut in half when a target peptide is bound. Here, two new crystal structures of calmodulin are presented, in which conformations possibly representing the first steps of calmodulin conformational collapse have been trapped. The central helix in the two structures is bent in the middle, causing a significant movement of the $\mathrm{N}$ - and C-terminal lobes with respect to one another. In both of the bent structures, a nearby polar side chain is inserted into the helical groove, disrupting backbone hydrogen bonding. The structures give an insight into the details of the factors that may be involved in the distortion of the central helix upon ligand peptide binding.

\section{Introduction}

Calmodulin $(\mathrm{CaM})$ is probably the most widely used model system for protein flexibility owing to its large-scale conformational changes upon ligand binding. Its EF-hands are activated by calcium binding, and the recognition of a target peptide leads to the collapse of the highly elongated dumbbell-shaped CaM into a nearly globular complex, with significant reductions in both the maximal molecular dimension and the radius of gyration. The first such 'canonical' CaM-peptide complexes were determined employing CaMbinding peptides from CaM-dependent protein kinases (CaMKs) using both X-ray crystallography and solution NMR spectroscopy (Ikura et al., 1992; Meador et al., 1992, 1993), and the observed collapsed conformation has ever since been considered to be a general property of $\mathrm{CaM}$-target protein complexes. The collapse of CaM upon CaMK peptide recognition involves disruption of the long central helix, allowing the two lobes to come together and bury the target peptide between them. It is likely that basic residues in the target sequence are involved in the disruption of the CaM central helix (Herring, 1991; Kuczera \& Kursula, 2012).

The canonical conformation of ligand-free $\mathrm{CaM}$ contains a long uninterrupted central helix, which collapses and bends into two shorter helices upon target protein binding. However, some CaM-peptide complexes have been described with a non-collapsed central helix (Majava et al., 2008; Majava \& Kursula, 2009; Liu et al., 2012; Kumar, Chichili, Zhong et al., 2013), and reports also exist of apo CaM conformations, in which the central helix is significantly bent (Fallon \& Quiocho, 2003; Yamada et al., 2012; Kumar, Chichili, Tang et al., 2013). Several simulation studies have also been carried out to show
Received 3 July 2013

Accepted 2 September 2013

PDB References: calmodulin, 4bw7; 4 bw 8 
that the central helix is unstable in the middle region, around residue 80 , and NMR studies in solution have come to similar conclusions (Ikura et al., 1991; Spera et al., 1991; Barbato et al., 1992; van der Spoel et al., 1996; Baber et al., 2001; Yang et al., 2001). A small bend around Asp80 is indeed present in some of the classical 'reference' crystal structures for the open CaM conformation, and the side chain of Glu84 may be implicated in this bending (Babu et al., 1988; Raghunathan et al., 1993; Rao et al., 1993; Rupp et al., 1996). Few experimental crystal structure data are available on the very first steps of central helix collapse, i.e. the situation in which the continuity of the central helix has just broken down and bending occurs. Additional structural data would enable the exact point of helix disruption to be pinpointed and would allow understanding of the factors that lead to structural collapse of calmodulin.

In addition to $\mathrm{Ca}^{2+}$ binding, the binding of other metal cations by $\mathrm{CaM}$ has also been of interest (Mills \& Johnson, 1985; Kursula \& Majava, 2007; Shirran \& Barran, 2009). In the case of strontium, for example, the motivation has been radioactive waste bioremediation (Rinaldo et al., 2004; Lepsík \& Field, 2007), while the binding of lead cations to CaM can be related to neurotoxicity (Sandhir \& Gill, 1994; Kursula \& Majava, 2007).

The structure of CaM was solved here from two crystals with translational pseudosymmetry, in which one monomer always has a continuous straight central helix while the second one is bent to varying degrees. These structures may correspond to the steps taking place when the open CaM structure starts to collapse and the central helix is divided in half.

\section{Methods}

$\mathrm{CaM}$ was purified and crystallized as described previously (Hayashi et al., 1998; Kursula \& Majava, 2007). Briefly, crystals were grown at $277 \mathrm{~K}$ using the hanging-drop method over a well containing mother liquor consisting of $40-50 \%$ MPD, $0.1 M$ sodium acetate $\mathrm{pH} 4$. Drops were prepared by mixing the CaM stock solution $\left(30 \mathrm{mg} \mathrm{ml}^{-1}\right.$ in $50 \mathrm{~m} M$ HEPES pH 7.5, $20 \mathrm{mM} \mathrm{CaCl}_{2}$ ) and the well solution in a 1:1 ratio, giving a starting concentration of $10 \mathrm{mM}$ for $\mathrm{Ca}^{2+}$ ions. Crystals suitable for diffraction studies appeared within a few days.

For further studies on metal binding by $\mathrm{CaM}$ in the crystalline state, soaking experiments were carried out in the well solution supplemented with either $15 \mathrm{mM} \mathrm{SrCl}_{2}$ or $10 \mathrm{~m} M$ EDTA, as described previously for the barium and lead complexes (Kursula \& Majava, 2007). Thereafter, the crystals were flash-cooled in a stream of gaseous nitrogen at $100 \mathrm{~K}$ without additional cryoprotection. Diffraction data were collected on the 1911-2 synchrotron radiation beamline at MAX-lab (Lund, Sweden) using a wavelength of $1.04 \AA$ and were processed using XDS (Kabsch, 2010) and XDSi (Kursula, 2004). The data were further analyzed using phenix.xtriage (Zwart et al., 2005) to detect possible twinning and pseudotranslation. Structure solution was carried out using Phaser (McCoy et al., 2007) with the crystal structure of chicken $\mathrm{Ca}^{2+}-\mathrm{CaM}$ (PDB entry 1up5; Rupp et al., 1996) as a
Table 1

Crystallographic data collection and structure refinement.

Values in parentheses are for the outer shell.

\begin{tabular}{|c|c|c|}
\hline & $\begin{array}{l}\text { Crystal form } 1 \\
\text { (EDTA-soaked) }\end{array}$ & $\begin{array}{l}\text { Crystal form } 2 \\
\text { ( } \mathrm{SrCl}_{2} \text {-soaked) }\end{array}$ \\
\hline Unit-cell parameters $\left(\AA{ }^{\circ}{ }^{\circ}\right)$ & $\begin{array}{c}a=24.4, b=53.9 \\
c=59.4, \alpha=88.5, \\
\beta=83.0, \gamma=86.4\end{array}$ & $\begin{array}{c}a=24.3, b=53.9 \\
c=59.4, \alpha=88.5 \\
\beta=96.6, \gamma=94.0\end{array}$ \\
\hline Space group & $P 1$ & $P 1$ \\
\hline Resolution range $(\AA)$ & $20-1.80(1.85-1.80)$ & $20-1.81(1.86-1.81)$ \\
\hline$R_{\text {merge }}(\%)$ & $5.7(43.8)$ & $4.9(26.5)$ \\
\hline$R_{\text {meas }}(\%)$ & $7.7(60.1)$ & $6.9(36.8)$ \\
\hline$\langle I / \sigma(I)\rangle$ & $10.8(1.9)$ & $10.8(2.4)$ \\
\hline Completeness (\%) & $92.4(84.5)$ & $93.9(82.1)$ \\
\hline Multiplicity & $2.1(1.8)$ & $2.0(1.6)$ \\
\hline $\mathrm{CC}_{1 / 2}(\%)$ & $99.5(62.8)$ & $99.5(80.3)$ \\
\hline Wilson $B$ factor $\left(\AA^{2}\right)$ & 23 & 22 \\
\hline$R_{\text {cryst }}(\%)$ & 23.6 & 20.6 \\
\hline$R_{\text {free }}(\%)$ & 27.9 & 25.1 \\
\hline R.m.s.d., bond lengths $(\AA)$ & 0.017 & 0.020 \\
\hline R.m.s.d., bond angles $\left({ }^{\circ}\right)$ & 1.6 & 1.7 \\
\hline \multicolumn{3}{|l|}{ Average $B$ factor $\left(\AA^{2}\right)$} \\
\hline Overall & 24.2 & 20.0 \\
\hline Protein & 24.5 & 19.5 \\
\hline Solvent & 18.8 & 25.8 \\
\hline MolProbity score [percentile] & $1.76[81 \mathrm{st}]$ & $1.53[93 \mathrm{rd}]$ \\
\hline \multicolumn{3}{|l|}{ Ramachandran plot (\%) } \\
\hline Favoured & 100 & 99.3 \\
\hline Outliers & 0 & 0 \\
\hline PDB code & 4bw8 & 4bw7 \\
\hline Pseudotranslation (\%) & 45 & 26 \\
\hline
\end{tabular}

model. To find the second monomer in these crystal forms, it was necessary to cut the search model in half in the middle of the long linker helix. Model building was performed in Coot (Emsley et al., 2010) and refinement was performed using phenix.refine (Adams et al., 2010), applying TLS parameterization as well as torsion-angle noncrystallographic symmetry (NCS) restraints. For structure validation and analysis, the programs MolProbity (Chen et al., 2010), Coot, SSM (Krissinel \& Henrick, 2004) and PyMOL (Schrödinger) were used. Data collection and refinement statistics are given in Table 1.

\section{Results}

The original aim of the current experiments was to follow metal binding by $\mathrm{CaM}$ in the crystalline state (Kursula \& Majava, 2007). The experiments included the soaking of $\mathrm{Ca}^{2+}$ loaded CaM crystals in either EDTA (crystal form 1) or strontium (crystal form 2). $\mathrm{Sr}^{2+}$ had replaced all of the $\mathrm{Ca}^{2+}$ ions in the crystal, as judged from the electron density after refinement (Fig. 1a). A simultaneous occupancy refinement of both $\mathrm{Sr}^{2+}$ and $\mathrm{Ca}^{2+}$ in all of the sites showed that in the first CaM monomer $73-100 \%$ of each site contained $\mathrm{Sr}^{2+}$ and in the bent monomer (see below) the $\mathrm{Sr}^{2+}$ content in the EF-hands was $45-52 \%$. Hence, despite reports of low affinity of CaM towards $\mathrm{Sr}^{2+}$ (Shirran \& Barran, 2009), $\mathrm{Ca}^{2+}$ could be replaced by $\mathrm{Sr}^{2+}$ relatively easily even in the crystalline state. EDTA did not remove $\mathrm{Ca}^{2+}$ from $\mathrm{CaM}$ in the crystalline state, except perhaps in the $\mathrm{C}$-terminal lobe of one monomer, which was rather disordered. This is not surprising, since the affinity of 

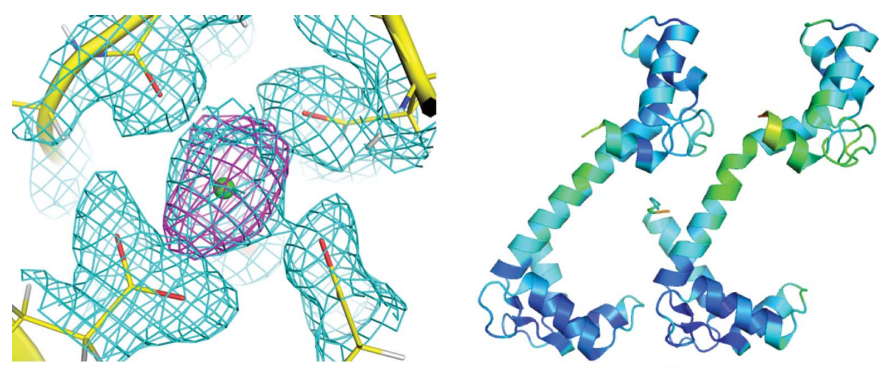

(a)

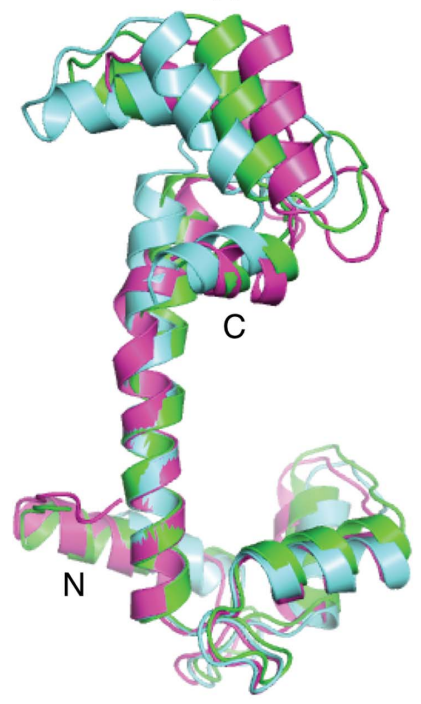

(b)

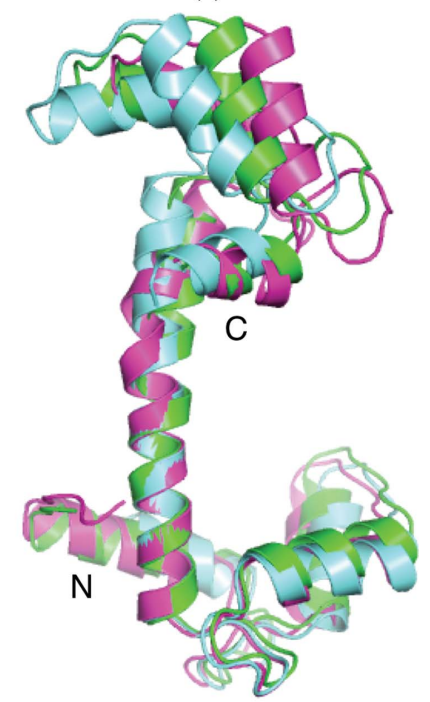

(c)

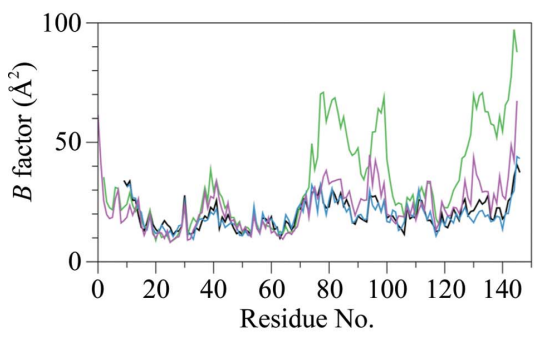

(d)

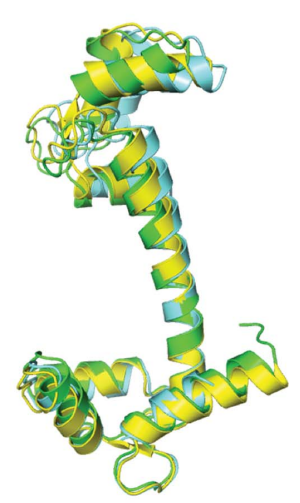

(e)
Figure 1

Overall structures of the observed conformations of CaM. (a) Electron density at EF-hand 2 of the non-bent monomer of crystal form 2 . The $\mathrm{Sr}$ atom is shown in green and the $2 F_{\mathrm{o}}-F_{\mathrm{c}}$ electron density is shown in cyan at a contour level of $1 \sigma$. The $F_{\mathrm{o}}-F_{\mathrm{c}}$ electron density at $4.0 \sigma$ when Ca was refined at the position of the $\mathrm{Sr}$ atom is shown in magenta. (b) The two monomers in crystal form 2 coloured by temperature factor. (c) The canonical monomer, with a straight central helix, from crystal form 2 is shown in light blue, the bent monomer from crystal form 1 in shown in green and the bent monomer from crystal form 2 is shown in magenta. The structures were superimposed based on the residue range 68-78, i.e. between the $\mathrm{N}$-terminal lobe and the site of bending. $(d)$ A temperaturefactor plot of the four CaM molecules in the current crystal forms. Straight and bent conformations of crystal form 1 are shown in black and green, respectively, and straight and bent conformations of crystal form 2 are shown in blue and magenta, respectively. (e) A comparison of the conformation of the straight helix (light blue), the bent monomer from crystal form 1 (green) and the original CaM structure with a small bend at Asp80 (yellow). It is clear that the bending is more pronounced in crystal form 1 than in the original CaM structure. For clarity, the view is rotated $180^{\circ}$ about the $y$ axis compared with that in $(c)$.
$\mathrm{CaM}$ for $\mathrm{Ca}^{2+}$ is high and its loss would lead to conformational changes, which are limited in the crystal as the EF-hands are heavily involved in crystal contacts.

During analysis of the structures, an interesting observation on the conformation of the CaM molecules in the crystal was made. Compared with earlier crystals from the same batch of protein and the very same crystallization experiment (Kursula $\&$ Majava, 2007), the $P 1$ unit cell in the current cases was twice the size, containing two CaM monomers instead of one. This type of arrangement was also previously observed for chicken CaM (Rupp et al., 1996). In the current case, this arrangement is coupled to significant pseudotranslational symmetry with the operator $(0,0,0.5): 26 \%$ in the Sr-soaked crystal and $45 \%$ in the EDTA-soaked crystal (Fig. 1b). Notably, a breakdown of NCS was further observed in both of the refined crystal structures. A closer look at the respective crystal structures revealed small but intriguing differences between the NCSrelated $\mathrm{CaM}$ monomers that may provide information on the first steps of $\mathrm{CaM}$ central helix collapse.

In both crystal forms, one of the $\mathrm{CaM}$ monomers has a continuous, straight central helix, being in the 'classical' unliganded $\mathrm{CaM}$ conformation, while the second monomer shows the presence of a bent helix. The degree of bending is different between the crystal forms, with a small bend in the EDTA-soaked crystal and a larger bend in the $\mathrm{Sr}^{2+}$ complex (Fig. 1c). Significant effects on the temperature factors are only apparent for the bent conformation in the EDTA-treated crystal (Fig. 1d). The hinge for this bending is located at residues $80-81$. In both crystal forms, a nearby side chain inserts at the point of bending and disrupts regular $\alpha$-helical hydrogen bonding (see below). The two benchmark structures of $\mathrm{Ca}^{2+}-\mathrm{CaM}$ are also not identical. While rat CaM (PDB entry 3clm) has a slight bend around Asp80 (Babu et al., 1988; Fig. 1e), chicken CaM (PDB entry 1up5; Rupp et al., 1996) has two molecules in the unit cell, one of which has a small bend and the other of which has a straight central helix.

The current structures reveal a possible direct role for nearby polar side chains, either in $\mathrm{CaM}$ or in the target protein, in bending the CaM central helix. In crystal form 1, the Glu84 side chain has turned towards the helix backbone; through making a hydrogen bond to the backbone carbonyl of Asp80 it prevents Asp80 from making the characteristic helix hydrogen bond to the $\mathrm{NH}$ group of Glu84, and the helix is slightly bent (Fig. 2). The region with most disorder in the disrupted helix spans residues 76-83. In this crystal form, the fourth EF-hand of the bent monomer is poorly ordered, which may indicate partial stripping of $\mathrm{Ca}^{2+}$ from the EF-hand by EDTA. A similar bend was observed in some of the earlier structures (Babu et al., 1988; Rupp et al., 1996). The other monomer in crystal form 1 has Glu84 pointing away from the helix.

In crystal form 2, the second CaM monomer is bent at the same location and to the same direction, but the bending angle is much larger at approximately $40^{\circ}$ (Figs. $1 b$ and $1 c$ ). Hence, it can be assumed that the conformation observed in crystal form 1 is intermediate between the intact straight central helix 


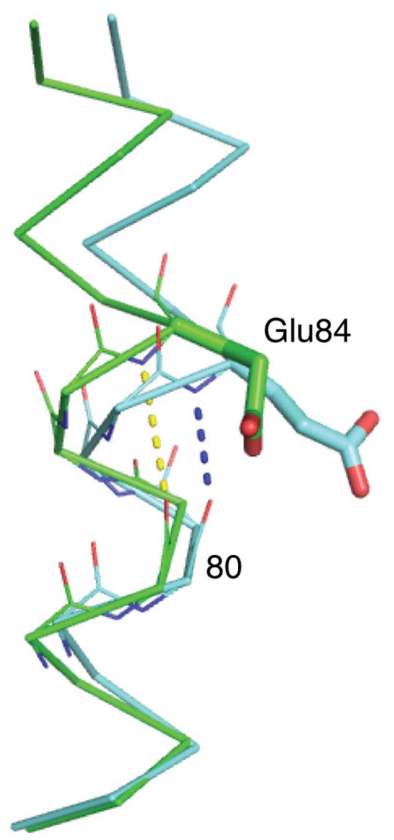

(a)

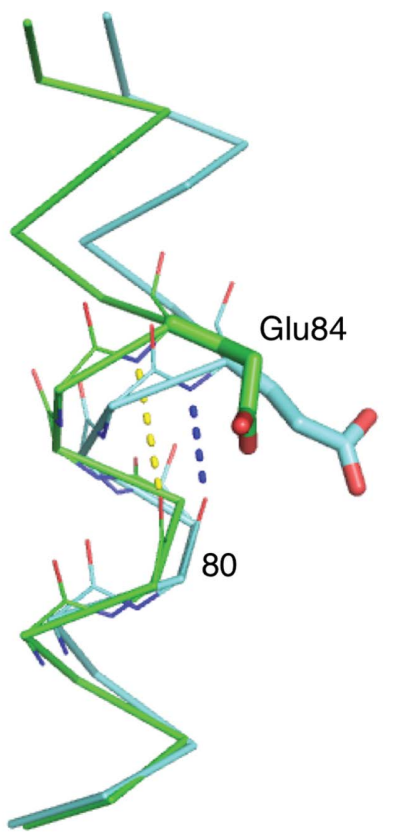

Figure 2

Central helix bending in crystal form 1. (a) Conformational change of Glu84 is linked to the loss (yellow) of a hydrogen bond between Asp80 and Glu84 (blue). The straight conformation is shown in cyan and the bent conformation is shown in green. (b) $2 F_{\mathrm{o}}-F_{\mathrm{c}}$ density for Glu84 in the bent chain contoured at $1 \sigma$.

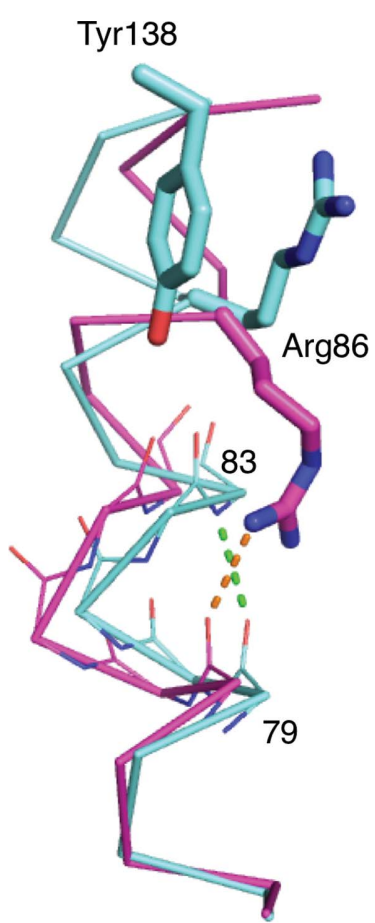

Figure 3

In crystal form 2, the central helix is bent by $40^{\circ}$, and the side chain of $\operatorname{Arg} 86$ flips inwards to distort hydrogen bonding in the helix backbone. (a) In the monomer with a straight central helix (cyan), Arg86 is stacked against Tyr138, but it hydrogen-bonds to the backbone amide of Thr79 in the bent conformation (magenta). (b) $2 F_{\mathrm{o}}-F_{\mathrm{c}}$ density for Arg86 in the bent chain contoured at $1 \sigma$.

and the conformation in crystal form 2 . The region around the bending hinge is very well defined in electron density and all residues could be built with high confidence.

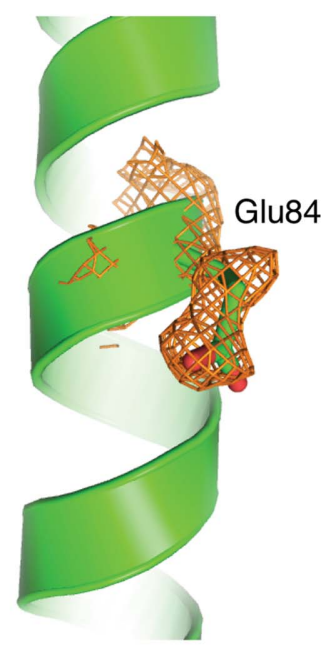

The bending in crystal form 2 is accompanied by a conformational change of Arg86 (Fig. 3). In the canonical CaM monomer in the same crystal, Arg86 is well defined and forms a $\pi$-stacking interaction with Tyr138 from the same chain. In the bent monomer, it has flipped over and makes a hydrogen bond to the backbone carbonyl of Thr79, effectively breaking the helix (Fig. 3a). A salt bridge between Arg86 and Glu82 has previously been detected in the extended-helix conformation (Babu et al., 1988; van der Spoel et al., 1996); in this case, Glu82 is also hydrogen-bonded to Tyr138. Such a salt bridge is not present in our structures; rather, Glu82 forms a hydrogen bond to Tyr138 only when Arg86 has flipped over to break the helix. In this structure, Arg86 may mimic a positively charged residue from a CaM target protein.

\section{Discussion}

$\mathrm{CaM}$ is a $17 \mathrm{kDa}$, highly acidic, bilobal, $\alpha$-helical protein containing a total of four EF-hands that bind calcium. $\mathrm{Ca}^{2+}$ binding results in conformational changes crucial to target protein recognition. The extended structure of $\mathrm{Ca}^{2+}-\mathrm{CaM}$ is supported by the presence of a long central helix (Babu et al., 1988); however, collapsed conformations have also been detected (Fallon \& Quiocho, 2003; Johnson, 2006; Gsponer et al., 2008; Yamada et al., 2012), suggesting an equilibrium between different conformational states in solution.

Several studies have been carried out on various mutant variants of the CaM central helix, including mutation or deletion of the acidic residues (Craig et al., 1987; Persechini et al., 1989, 1991; Gulati et al., 1990; VanBerkum et al., 1990; Raghunathan et al., 1993; Medvedeva et al., 1995, 1999; Tabernero et al., 1997). In general, the outcome has been CaM that has been functional but with a lower affinity towards target proteins. Both fully 
extended and bent conformations have been described for these mutants (Kataoka et al., 1991; Raghunathan et al., 1993), and the consensus remains that the consecutive acidic residues in the middle of the central helix promote helix destabilization through their mutual electrostatic repulsion.

With regard to Glu84, both deletion mutants as well as the point mutant E84K have been described. E84K is a variant

Table 2

Comparison to existing reference structures of CaM.

R.m.s.d. values (in $\AA$ ) for $\mathrm{C}^{\alpha}$ atoms between the different chains in the current structures and reference structures from the PDB are shown as defined by PDBeFold (Krissinel \& Henrick, 2004). While the bent conformation of crystal form 1 is similar to the $A$ chain of chicken CaM (PDB entry 1up5), the bent conformation in crystal form 2 is unique. Two structures of open $\mathrm{CaM}$ with bound peptides are also included for comparison. The numbers in parentheses correspond to the distance between the carbonyl $\mathrm{O}$ atom of Asp80 and the backbone $\mathrm{N}$ atom of Glu84 (in $\AA$ ).

\begin{tabular}{lllll}
\hline PDB entry & $\begin{array}{l}\text { Crystal form 1: } \\
\text { straight (3.2) }\end{array}$ & $\begin{array}{l}\text { Crystal form 1: } \\
\text { bent (3.8) }\end{array}$ & $\begin{array}{l}\text { Crystal form 2: } \\
\text { straight (3.0) }\end{array}$ & $\begin{array}{l}\text { Crystal form 2: } \\
\text { bent (5.1) }\end{array}$ \\
\hline 3cln (3.8) (Babu et al., 1988) & 0.70 & 1.30 & 0.65 & 1.92 \\
1up5 chain A (3.2) (Rupp et al., 1996) & 1.35 & 0.58 & 1.36 & 1.09 \\
1up5 chain B (3.0) (Rupp et al., 1996) & 0.45 & 1.43 & 0.51 & 1.85 \\
4ehq (Liu et al., 2012) & 0.71 & 1.39 & 0.63 & 1.91 \\
2w73 (Majava \& Kursula, 2009) & 1.96 & 1.97 & 1.90 & 2.62 \\
\hline
\end{tabular}

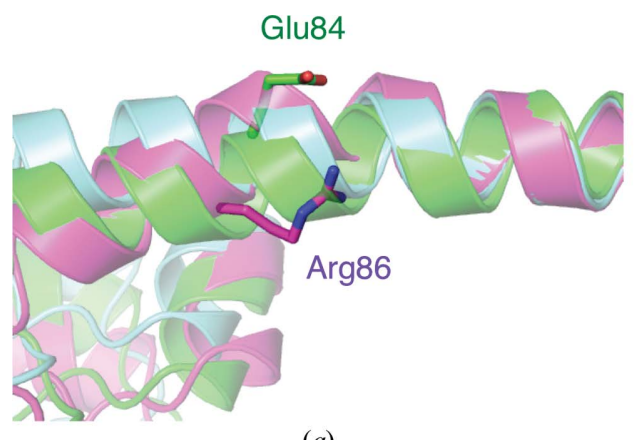

(a)

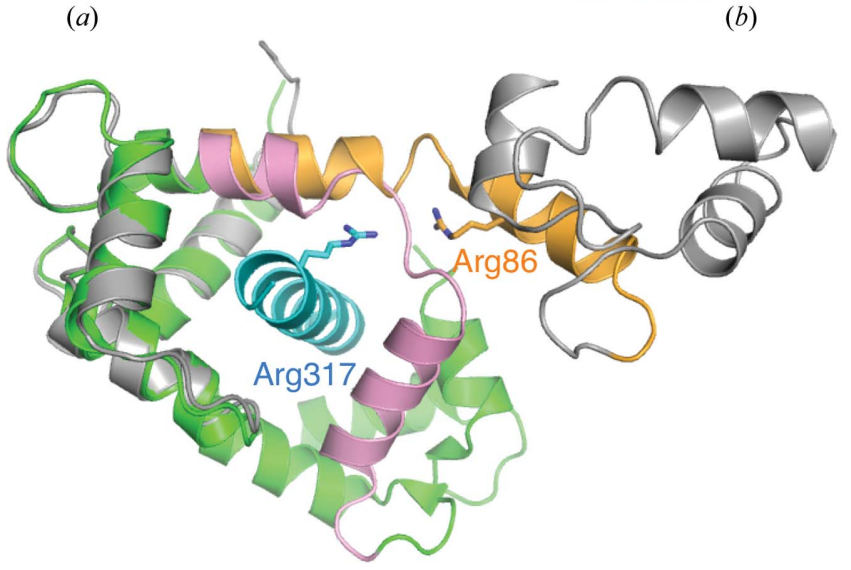

(c)

\section{Figure 4}

The relative positions of Glu84 and Arg86 of CaM and an arginine from a ligand peptide. (a) When swinging in to interact with the backbone, the two residues in the two crystal forms reach towards the same position: the helical groove between residues 79-80 and 83-84. (b) The complex between CaM and a peptide from DAP kinase (de Diego et al., 2010; PDB entry 1yr5) shows an interaction between the backbone of the disrupted helix, including Thr79, and the side chain of Arg317 from the peptide. A salt bridge is also present between Glu84 and this arginine residue, while Arg86 is far away from the peptide and in fact interacts with Tyr138. (c) A comparison between the bent conformation (grey; central linker in orange) and the fully collapsed peptide complex (green; central linker in pink) shows that the bending region corresponds to that required for complex formation. In both structures, an arginine residue interacts with the unfolded central helix backbone.

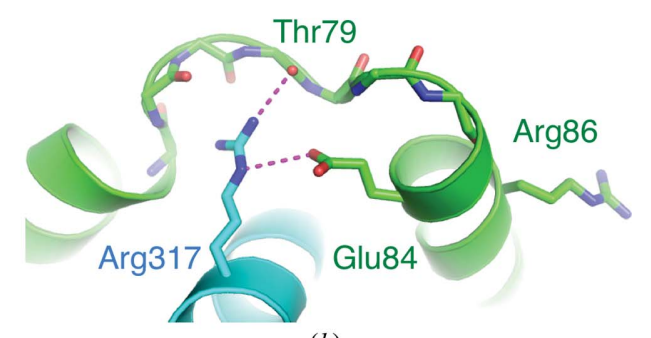

(b) that fails to complement the endogenous gene when imported into CaM-deficient yeast (Harris et al., 1994). des84-CaM was crystallized as a bent molecule (Raghunathan et al., 1993), while it has been shown that it has a more open conformation any case, structural results from deletion mutants should be or example in the case of the CaM central helix, they will significantly affect the relative orientations of separate domains to one another by default even in the case where the helical conformation is not disrupted (Tabernero et al., 1997). For Arg86, few examples of mutations are available, but the consensus from such experiments and simulations is that mutations have little effect on $\mathrm{CaM}$ structure and function (Weinstein \& Mehler, 1994; Kong Au \& Chow Leung, 1998).

Recently, a bent conformation of unliganded $\mathrm{CaM}$ was reported (Kumar, Chichili, Tang et al., 2013), but in this case, the central helix had a bending angle of $90^{\circ}$, which does not correspond to an initial state of helix deformation. On the other hand, in recent years, a number of reports have documented CaM-peptide complexes, in which $\mathrm{CaM}$ does not collapse at all (Majava et al., 2008; Majava \& Kursula, 2009; Liu et al., 2012; Kumar, Chichili, Zhong et al., 2013). It could be that these peptides lack a correctly positioned basic residue that can trigger helix bending, and the affinity in these cases is likely to be lower than in the classical collapsed complexes, which have $K_{\mathrm{d}}$ values in the nanomolar range.

A search of CaM conformations in the PDB confirms the above findings. The closest matches for the straight central helix conformations are distinct from the bent conformations. Specifically, the bent conformation of crystal form 2 is clearly distinct from other structures in the PDB (Table 2). A characteristic measure of the disruption of the central helix is the distance between the carbonyl $\mathrm{O}$ atom of 
Asp80 and the peptide $\mathrm{N}$ atom of Glu84, which was originally noted to be $3.8 \AA$ in the extended but slightly bent conformation (Babu et al., 1988). These values (Table 2) also support the observations on the degree of helix bending, with a straight helix having a hydrogen-bonding distance of $3.0 \AA$ at this location. Another measure used in single-molecule and NMR experiments (Johnson, 2006; Gsponer et al., 2008) is the distance between residues 34 and 110. Even in the most bent structure here, this distance is $51 \AA$, clearly classifying it as an 'open' conformation, while the collapsed conformations have a value of around $30 \AA$. Hence, much greater conformational flexibility has been observed in solution than is observed here in the crystal state; this is as expected and further highlights the fact that an intermediate structure of a highly dynamic molecule has been trapped in $50 \%$ of the molecules in crystal form 2.

The structural data presented here confirm the presence of a hot spot in the close vicinity of Asp 80 in the CaM central helix backbone, which can be broken by the approach of a suitable side chain. In the cases described here, the side chain was Glu84 or Arg86, which both interact with the same helical turn in the bent conformation (Fig. 4a). Upon ligand peptide or target protein binding, it is likely that a basic side chain from the binding partner can perform similarly, leading to full $\mathrm{CaM}$ collapse. Such interactions can be observed in collapsed CaM-peptide complexes: a very good example is the complex between CaM and a peptide from DAP kinase (de Diego et al., 2010), in which the disrupted segment of the central helix is also fully defined in the crystal structure (Fig. 4b). This structure, for example, shows an interaction between Arg317 of the peptide and CaM residue 79. Superposing the peptide complex on the bent conformation highlights a common location for these interactions in both cases (Fig. 4c), supporting the view that Arg86 in the bent structure from crystal form 2 mimics a positive ligand residue. Thus, the formation of a CaM-peptide complex may in the initial stages resemble the bent $\mathrm{CaM}$ structures presented in this work.

The beamtime and the excellent beamline support at MAXlab are gratefully acknowledged, as are stimulating discussions with Dr Inari Kursula. This study has been financially supported by the Academy of Finland, the Sigrid Jusélius Foundation and the Hamburg Research and Science Foundation. The use of beamtime at MAX-lab was supported by the European Community Research Infrastructure Action under the FP6 'Structuring the European Research Area' Programme (through the Integrated Infrastructure Initiative 'Integrating Activity on Synchrotron and Free Electron Laser Science').

\section{References}

Adams, P. D. et al. (2010). Acta Cryst. D66, 213-221.

Baber, J. L., Szabo, A. \& Tjandra, N. (2001). J. Am. Chem. Soc. 123, 3953-3959.

Babu, Y. S., Bugg, C. E. \& Cook, W. J. (1988). J. Mol. Biol. 204, 191-204.

Barbato, G., Ikura, M., Kay, L. E., Pastor, R. W. \& Bax, A. (1992). Biochemistry, 31, 5269-5278.
Chen, V. B., Arendall, W. B., Headd, J. J., Keedy, D. A., Immormino, R. M., Kapral, G. J., Murray, L. W., Richardson, J. S. \& Richardson, D. C. (2010). Acta Cryst. D66, 12-21.

Craig, T. A., Watterson, D. M., Prendergast, F. G., Haiech, J. \& Roberts, D. M. (1987). J. Biol. Chem. 262, 3278-3284.

Diego, I. de, Kuper, J., Bakalova, N., Kursula, P. \& Wilmanns, M. (2010). Sci. Signal. 3, ra6.

Emsley, P., Lohkamp, B., Scott, W. G. \& Cowtan, K. (2010). Acta Cryst. D66, 486-501.

Fallon, J. L. \& Quiocho, F. A. (2003). Structure, 11, 1303-1307.

Gsponer, J., Christodoulou, J., Cavalli, A., Bui, J. M., Richter, B., Dobson, C. M. \& Vendruscolo, M. (2008). Structure, 16, 736-746.

Gulati, J., Persechini, A. \& Babu, A. (1990). FEBS Lett. 263, 340-344.

Harris, E., Watterson, D. M. \& Thorner, J. (1994). J. Cell Sci. 107, 3235-3249.

Hayashi, N., Matsubara, M., Takasaki, A., Titani, K. \& Taniguchi, H. (1998). Protein Expr. Purif. 12, 25-28.

Herring, B. P. (1991). J. Biol. Chem. 266, 11838-11841.

Ikura, M., Clore, G. M., Gronenborn, A. M., Zhu, G., Klee, C. B. \& Bax, A. (1992). Science, 256, 632-638.

Ikura, M., Spera, S., Barbato, G., Kay, L. E., Krinks, M. \& Bax, A. (1991). Biochemistry, 30, 9216-9228.

Johnson, C. K. (2006). Biochemistry, 45, 14233-14246.

Kabsch, W. (2010). Acta Cryst. D66, 125-132.

Kataoka, M., Head, J. F., Persechini, A., Kretsinger, R. H. \& Engelman, D. M. (1991). Biochemistry, 30, 1188-1192.

Kataoka, M., Persechini, A., Tokunaga, F. \& Kretsinger, R. H. (1996). Proteins, 25, 335-341.

Kong Au, T. \& Chow Leung, P. (1998). Plant Physiol. 118, 965-973.

Krissinel, E. \& Henrick, K. (2004). Acta Cryst. D60, 2256-2268.

Kuczera, K. \& Kursula, P. (2012). J. Biomol. Struct. Dyn. 30, 45-61.

Kumar, V., Chichili, V. P. R., Tang, X. \& Sivaraman, J. (2013). PLoS One, 8, e54834.

Kumar, V., Chichili, V. P. R., Zhong, L., Tang, X., Velazquez-Campoy, A., Sheu, F.-S., Seetharaman, J., Gerges, N. Z. \& Sivaraman, J. (2013). Sci Rep. 3, 1392.

Kursula, P. (2004). J. Appl. Cryst. 37, 347-348.

Kursula, P. \& Majava, V. (2007). Acta Cryst. F63, 653-656.

Lepsík, M. \& Field, M. J. (2007). J. Phys. Chem. B, 111, 10012-10022.

Liu, Y., Zheng, X., Mueller, G. A., Sobhany, M., DeRose, E. F., Zhang, Y., London, R. E. \& Birnbaumer, L. (2012). J. Biol. Chem. 287, 43030-43041.

Majava, V. \& Kursula, P. (2009). PLoS One, 4, e5402.

Majava, V., Petoukhov, M. V., Hayashi, N., Pirilä, P., Svergun, D. I. \& Kursula, P. (2008). BMC Struct. Biol. 8, 10.

McCoy, A. J., Grosse-Kunstleve, R. W., Adams, P. D., Winn, M. D., Storoni, L. C. \& Read, R. J. (2007). J. Appl. Cryst. 40, 658-674.

Meador, W. E., Means, A. R. \& Quiocho, F. A. (1992). Science, 257, 1251-1255.

Meador, W. E., Means, A. R. \& Quiocho, F. A. (1993). Science, 262, $1718-1721$.

Medvedeva, M. V., Bushueva, T. L., Shirinsky, V. P., Lukas, T. J., Watterson, D. M. \& Gusev, N. B. (1995). FEBS Lett. 360, 89-92.

Medvedeva, M. V., Polyakova, O. V., Watterson, D. M. \& Gusev, N. B. (1999). FEBS Lett. 450, 139-143.

Mills, J. S. \& Johnson, J. D. (1985). J. Biol. Chem. 260, 15100-15105.

Persechini, A., Blumenthal, D. K., Jarrett, H. W., Klee, C. B., Hardy, D. O. \& Kretsinger, R. H. (1989). J. Biol. Chem. 264, 80528058.

Persechini, A., Kretsinger, R. H. \& Davis, T. N. (1991). Proc. Natl Acad. Sci. USA, 88, 449-452.

Raghunathan, S., Chandross, R. J., Cheng, B. P., Persechini, A., Sobottka, S. E. \& Kretsinger, R. H. (1993). Proc. Natl Acad. Sci. USA, 90, 6869-6873.

Rao, S. T., Wu, S., Satyshur, K. A., Ling, K.-Y., Kung, C. \& Sundaralingam, M. (1993). Protein Sci. 2, 436-447.

Rinaldo, D., Vita, C. \& Field, M. J. (2004). J. Biomol. Struct. Dyn. 22, 281-297. 


\section{research papers}

Rupp, B., Marshak, D. R. \& Parkin, S. (1996). Acta Cryst. D52, 411-413.

Sandhir, R. \& Gill, K. D. (1994). Exp. Mol. Pathol. 61, 69-75.

Shirran, S. L. \& Barran, P. E. (2009). J. Am. Soc. Mass Spectrom. 20, 1159-1171.

Spera, S., Ikura, M. \& Bax, A. (1991). J. Biomol. NMR, 1, 155165.

Spoel, D. van der, de Groot, B. L., Hayward, S., Berendsen, H. J. C. \& Vogel, H. J. (1996). Protein Sci. 5, 2044-2053.

Tabernero, L., Taylor, D. A., Chandross, R. J., VanBerkum, M. F., Means, A. R., Quiocho, F. A. \& Sack, J. S. (1997). Structure, 5,
$613-622$.

VanBerkum, M. F., George, S. E. \& Means, A. R. (1990). J. Biol. Chem. 265, 3750-3756.

Weinstein, H. \& Mehler, E. L. (1994). Annu. Rev. Physiol. 56, 213-236.

Yamada, Y., Matsuo, T., Iwamoto, H. \& Yagi, N. (2012). Biochemistry, 51, 3963-3970.

Yang, C., Jas, G. S. \& Kuczera, K. (2001). J. Biomol. Struct. Dyn. 19, 247-271.

Zwart, P. H., Grosse-Kunstleve, R. W. \& Adams, P. D. (2005). CCP4 Newsl. Protein Crystallogr. 43, 27-35. 